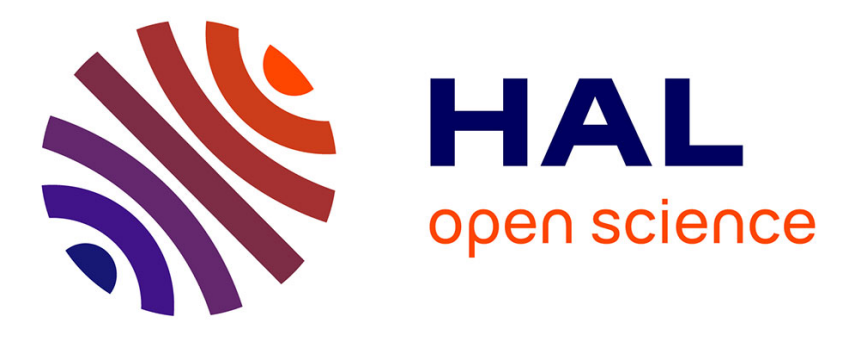

\title{
Sedimentation study of biphasic calcium phosphate particles
}

Ahmed Fatimi, Jean-François Tassin, Monique A. V. Axelos, Pierre Weiss

\section{To cite this version:}

Ahmed Fatimi, Jean-François Tassin, Monique A. V. Axelos, Pierre Weiss. Sedimentation study of biphasic calcium phosphate particles. Key Engineering Materials, 2007, 361-363, pp.365-368. 10.4028/www.scientific.net/KEM.361-363.365 . inserm-00383360

\section{HAL Id: inserm-00383360 https://www.hal.inserm.fr/inserm-00383360}

Submitted on 13 May 2009

HAL is a multi-disciplinary open access archive for the deposit and dissemination of scientific research documents, whether they are published or not. The documents may come from teaching and research institutions in France or abroad, or from public or private research centers.
L'archive ouverte pluridisciplinaire HAL, est destinée au dépôt et à la diffusion de documents scientifiques de niveau recherche, publiés ou non, émanant des établissements d'enseignement et de recherche français ou étrangers, des laboratoires publics ou privés. 


\title{
Sedimentation Study of Biphasic Calcium Phosphate Particles
}

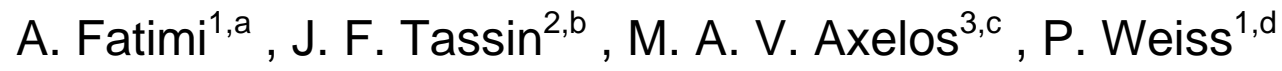 \\ ${ }^{1}$ LIOAD, INSERM U791, Université de Nantes, 1 place Alexis Ricordeau, 44042 Nantes, France. \\ ${ }^{2}$ Polymères, Colloïdes, Interfaces, Université du Maine, CNRS UMR6120, 72085 Le Mans, France. \\ ${ }^{3}$ Biopolymères, Interactions, Assemblages, INRA UR1268, 44300 Nantes Cedex 03, France. \\ aahmed.fatimi@univ-nantes.fr, bjean-francois.tassin@univ-lemans.fr,

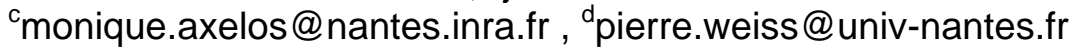

Keywords: biphasic calcium phosphate, cellulose ether derivatives, sedimentation, viscosity.

\begin{abstract}
Injectable calcium phosphate $(\mathrm{CaP})$ biomaterial is considered as an injectable bone substitute (IBS). It was developed to minimize invasive surgery in various applications in orthopedic and dental surgery. The IBS considered of a polymer solution mixed with biphasic calcium phosphate (BCP) ceramic particles. Two particle sizes of BCP $(40-80$ and $80-200 \mu \mathrm{m})$ were used and the weight ratio was $40 \%$. This study investigated the influence of polymer solution on the BCP particles stability. Effects of particles size and limiting viscosity of polymer on the sedimentation were studied. The polymer concentration and particles size can be adapted to provide the best stability and storage of IBS.
\end{abstract}

\section{Introduction}

Calcium phosphate $(\mathrm{CaP})$ ceramics are the main raw materials used to elaborate granules for bone substitutes. These ceramics are being increasingly used in orthopedic surgery, maxillo facial surgery and dental applications because of their bioactive properties. The concept of injectable bone substitute (IBS) developed in our laboratory is based on association of biphasic calcium phosphate (BCP) granules and a cellulose ether derivative polymer [1,2]. IBS requires suitable rheological properties to ensure bonding of the mineral phase in situ with good cell permeability.

The BCP mineral phase is an association of hydroxyapatite (HA) and $\beta$-tricalcium phosphate $(\beta$ TCP). The suitable proportions of HA $(60 \%)$ and $\beta$-TCP $(40 \%)$ has provided BCP ceramics with controlled bioactivity and biocompatibility [3]. The viscous phase of IBS is an aqueous polymer solution (hydroxypropylmethylcellulose (HPMC) or sodium carboxymethylcellulose (CMC)). They are biocompatible and nontoxic polymers.

Although several works have been focused on various properties of cellulose ether derivative such as water affinity [4] and gelation [5, 6], the rheological properties of these carbohydrate polymers were largely studied [7-9] with many interpretations. Cellulose ether derivative gives the consistency form to IBS. Apparent viscosity and consistency of IBS is based on different parameters (concentration and type of polymer, particles size and ratio of BCP). IBS formulation is an essential factor for rheological properties and injectability [10]. To show better injectability and avoid demixing phenomena and filter pressing of IBS during injection from the syringe, BCP particles must be stable in polymer solution. During storage, the particles settle out as a consequence of gravitational force. This physical phenomenon, sedimentation, is observed in various engineering fields such as chemical engineering, materials and pharmaceuticals processing [11]. A lot of studies have been devoted to the understanding of the stability of suspensions or settling phenomena from a fundamental point of view. Information on particle size, packing density and the mechanism of settling for both dispersant and sediment system have been discussed by Allain et al. [12] and Balastre et al. [13]. Different approaches have been proposed to describe the hindered settling process. Most of them consider the hindrance dependant on the volume fraction of solids only.

The aim of this work was to study the stability of IBS by investigating the sedimentation of BCP particles in different aqueous polymer solutions at fixed volume fraction of solids. 


\section{Materials and methods}

Polymer solutions were prepared at different concentration in deionized water. The characteristic samples are given in Table 1. The BCP particles used in this study were prepared in our laboratory by precipitation of calcium-deficient apatite (CDA) and sintering [3]. Image observations (Fig. 1) and granulometry analysis (Fig. 2) of BCP particles were realized using scanning electron microscopy (LEO $1450 \mathrm{VP}$, Germany). Different preparations of IBS were made by mixing BCP particles $(40-80$ or $80-200 \mu \mathrm{m}$ in diameter) with different polymer solutions at fixed ratio $(40 \%$ $\mathrm{w} / \mathrm{w})$. The limiting viscosities of different polymer solutions were obtained at low shear-rate from flow curves. Rheological measurements were performed using RheoStress 300 (ThermoHaake ${ }^{\circledR}$, Germany) with cone and plate geometry $\left(\mathrm{C} 60 / 1^{\circ} \mathrm{Ti}\right)$. The polymer densities were also determined at $25^{\circ} \mathrm{C}$. The sedimentation study was realized at $25^{\circ} \mathrm{C}$ and the $\mathrm{BCP}$ particles boundary variations for each polymer solution were determined visually as a function time. Water was used as a control. The percentage of solid phase volume settled as a function of time was calculated according to the following formula:

$$
\text { Volume }=100 \frac{V_{t}}{V_{0}}
$$

where $V_{t}$ is the volume of settled phase at a given time and $V_{0}$ is the initial volume occupied by the suspension.
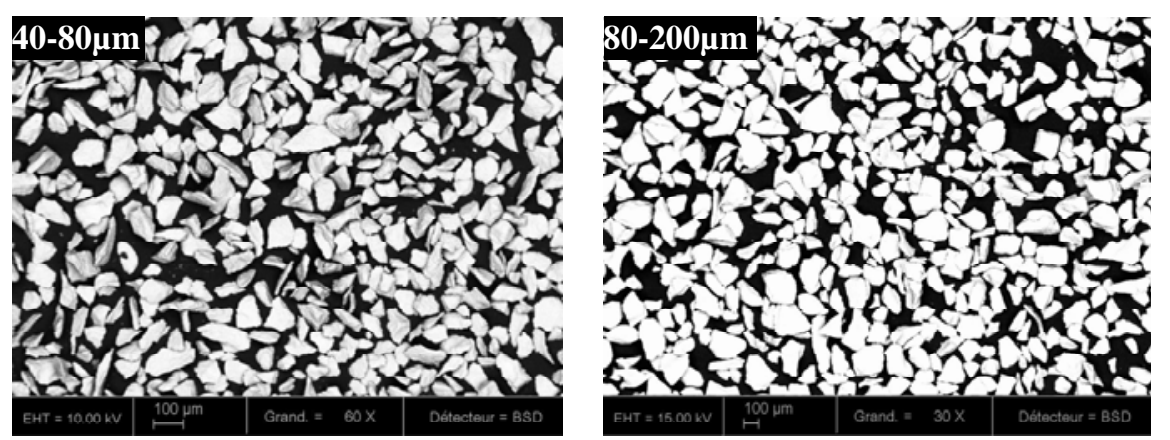

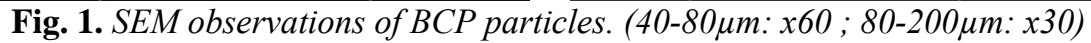

\section{Results}

The flow curves of E4M, Blanose, Benecel, K4M and $\mathrm{K} 15 \mathrm{M}$ polymer solutions obtained had a similar profile. They all showed a Newtonian zone at low shear-rate and they exhibited a shearthinning at high shear-rate. The limiting viscosities (zero shear viscosity $\eta_{0}$ ) were obtained at relatively low shear rates using the Cross equation.

Table 1 shows the limiting viscosities obtained for different polymer solutions. The results show that an increase of $\eta_{0}$ with the polymer concentration, this phenomenon is usual for polysaccharides where the $\eta_{0}$ value becomes higher as the polymer concentration rises [14]. The size distribution of BCP particles determined before mixing with polymer solutions are shown in Fig. 2. The distributions clearly display a maximum for each granulometry and the mean diameters were 70 and $170 \mu \mathrm{m}$ for $40-80 \mu \mathrm{m}$ and $80-200 \mu \mathrm{m}$ granulometry, respectively.
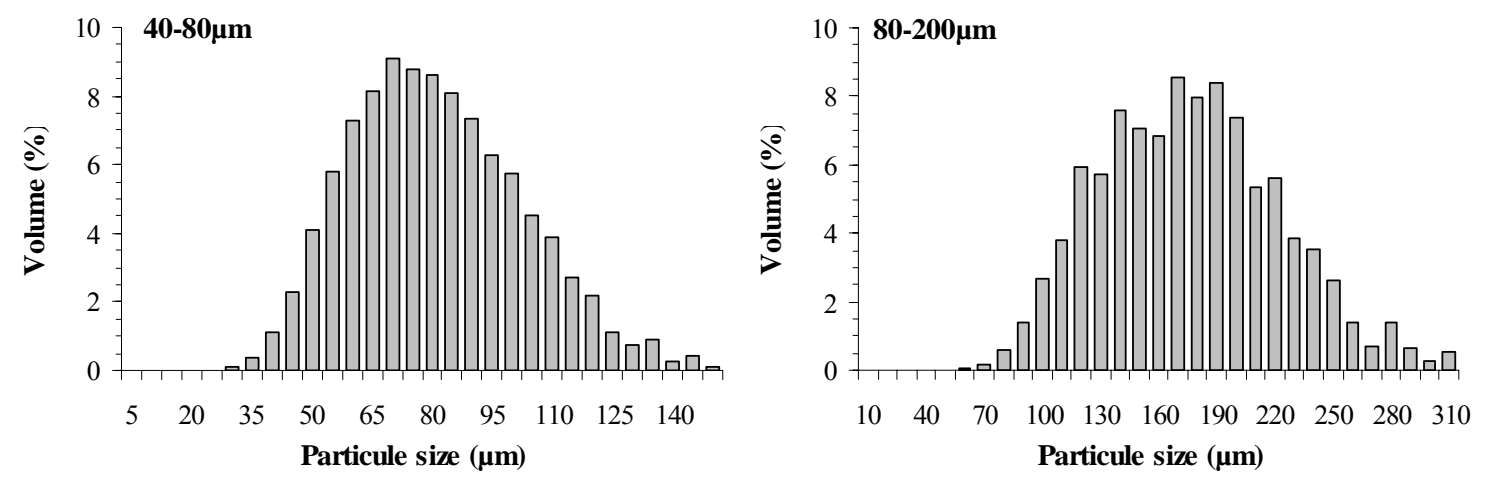

Fig. 2. Size distribution of $B C P$ particles. 
Table 1. Characteristics of polymer samples used in the present work.

\begin{tabular}{|c|c|c|c|c|c|}
\hline Polymer & Type & $\begin{array}{l}\text { Methoxyl degree } \\
\text { of substitution }\end{array}$ & $\begin{array}{l}\text { Concentration } \\
(\%)\end{array}$ & $\begin{array}{l}\text { Density } \rho_{f} \\
\left(\mathrm{~kg} \cdot \mathrm{dm}^{-3}\right)\end{array}$ & $\begin{array}{l}\text { Limiting viscosity } \eta_{0} \\
\text { (Pa.s) }\end{array}$ \\
\hline \multirow[t]{2}{*}{ Methocel ${ }^{\circledR}$ E4M } & HPMC & 1.9 & 1.0 & $1.04 \pm 0.07$ & $0.10 \pm 0.02$ \\
\hline & & & 2.0 & $1.10 \pm 0.15$ & $1.50 \pm 0.14$ \\
\hline \multirow[t]{2}{*}{ Blanose $^{\circledR} 7 \mathrm{H} 4 \mathrm{XF}$} & $\mathrm{CMC}$ & 0.7 & 1.0 & $1.05 \pm 0.10$ & $0.43 \pm 0.01$ \\
\hline & & & 2.0 & $1.08 \pm 0.05$ & $3.86 \pm 0.07$ \\
\hline \multirow[t]{2}{*}{ Benecel $^{\circledR}$ MP824 } & HPMC & 1.4 & 1.0 & $1.05 \pm 0.10$ & $0.50 \pm 0.03$ \\
\hline & & & 2.0 & $1.25 \pm 0.29$ & $6.73 \pm 1.21$ \\
\hline Methocel ${ }^{\circledR} \mathrm{K} 4 \mathrm{M}$ & HPMC & 1.4 & 2.0 & $1.05 \pm 0.04$ & $1.52 \pm 0.02$ \\
\hline Methocel $^{\circledR}$ K15M & HPMC & 1.4 & 1.5 & $1.01 \pm 0.02$ & $1.39 \pm 0.02$ \\
\hline
\end{tabular}
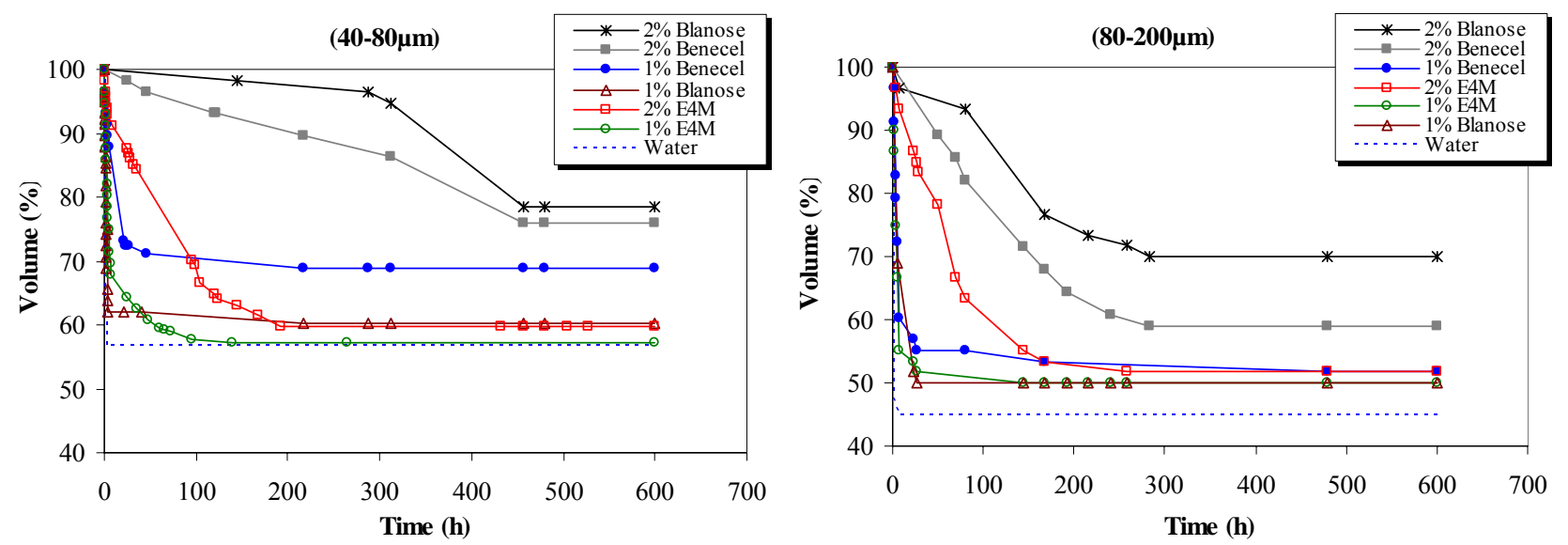

Fig. 3. Kinetics of sedimentation of BCP particles dispersed in different polymer solutions.

Fig. 3 shows kinetics of sedimentation of BCP dispersed in different polymer solutions. The water shows a maximal compactness (i.e. volume fraction inside the sediment at equilibrium). The effect of particles size was observed. The sediment compactness for $40-80 \mu \mathrm{m}$ particles $(57 \sim 79 \%)$ was qualitatively much larger than $80-200 \mu \mathrm{m}$ one $(45 \sim 70 \%)$. This difference is due to the diameter of $\mathrm{BCP}$ particles. The influence of polymer solution was also remarked.

The influence of type of polymer on sedimentation velocity was studied (Fig. 4). K4M and K15M polymers with the same $\eta_{0}(1.39 \sim 1.52 \mathrm{~Pa} . \mathrm{s})$ were used in this study. Kinetics of sedimentation shows that for both polymers, the sedimentation velocity of the particles was the same.

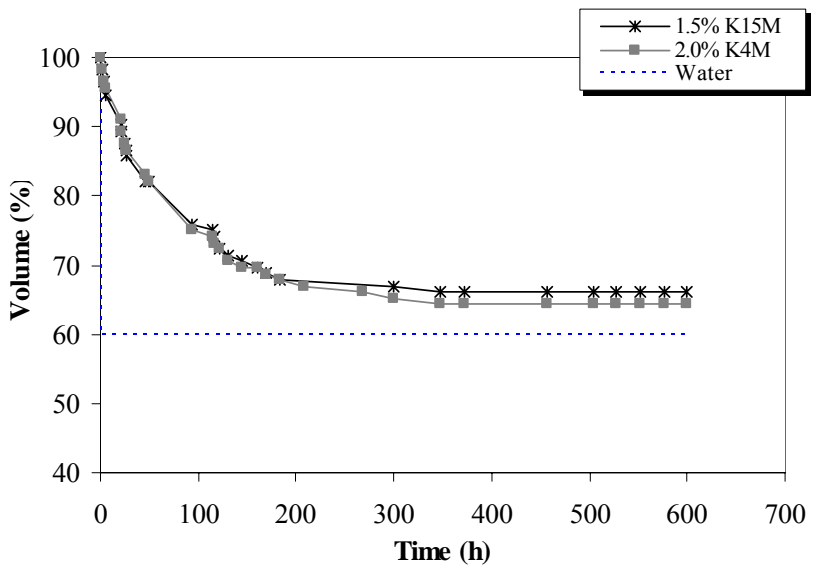

Fig. 4. Kinetics of sedimentation of BCP particles (40$80 \mu \mathrm{m})$ dispersed in two different polymer solutions with

$$
\text { the same } \eta_{0 .}
$$

The relative settling velocity can be calculated using Stokes law:

$$
u=\frac{d^{2}\left(\rho_{s}-\rho_{f}\right) g}{18 \eta_{0}}
$$

where $u\left(\mathrm{~m}^{-1}{ }^{-1}\right)$ is the terminal velocity or Stokes velocity, $\rho_{s}\left(\mathrm{~kg} \cdot \mathrm{m}^{-3}\right)$ and $\rho_{f}\left(\mathrm{~kg} \cdot \mathrm{m}^{-3}\right)$ are the density of the solid particles and liquid, respectively, $d(\mathrm{~m})$ is the diameter of the particle, $g$ is the gravity acceleration $\left(9.8 \mathrm{~m} \cdot \mathrm{s}^{-2}\right)$ and $\eta_{0}$ (Pa.s) is the limiting viscosity of the suspending liquid.

Stokes law (Eq. 2) is applicable only if the Reynolds number $(\mathrm{Re})$ is less than 2 :

$$
\operatorname{Re}=\frac{\rho_{f} u d_{p}}{\eta_{0}}
$$

In this study, both $\mathrm{BCP}$ granulometries present $\mathrm{Re}<2$, meaning that the $\mathrm{BCP}$ particles studied here were in the Stokes sedimentation region. 


\section{Discussion}

Although the Stokes law is a simple expression for the settling velocity; it is valid only for infinite dilution in which the particles are not affected by each other and the tube walls. In practice, settling velocity is affected by many factors. The important factor is the concentration of particles. In concentrated suspensions, the settling velocity is influenced by the interparticle forces which normally reduce the settling velocity with respect to Stokes velocity. This process is commonly referred to as hindered settling. The hindered settling is found to be a function of solid concentration. This study was realized at fixed concentration of particles (40\%). Another important factor is the viscosity of suspending liquid. Theoretically, the high polymer viscosity decreases the sedimentation velocity. The BCP particles became separated from each other by the macromolecular network. It consists of (i) adsorbed polymer chains, (ii) interaction between adsorbed chains and free polymer chain in solution, (iii) compression of the polymer network attached or interacting with particles. With water, the compactness of BCP particles was maximal (Fig. 3). The sedimentation velocity results from a balance between the net gravity force and the hydrodynamic force arising from the flow of the solvent through the particle network [13].

The effect of the particles size on the sedimentation process is observed in Fig. 3. At fixed volume fraction, it is found that the particles with larger size lead to a more rapid and significant settling, the BCP particles with $40-80 \mu \mathrm{m}$ settle less than BCP particles with $80-200 \mu \mathrm{m}$. Type of polymer doesn't play a large role in sedimentation kinetic and compactness. For different polymers with the same zero shear viscosity, settling velocity and sediment compactness of the particle are the same.

\section{Conclusions}

Reynolds number indicates that sedimentation of BCP particles was in the laminar flow region (Stokes region). Storage of IBS could be controlled essentially by concentration and size of particles and limiting viscosity of polymer.

Sterilization is another parameter which seems to play an important role in sedimentation kinetic. As steam sterilization has to be done for medical reasons, it is necessary to prevent eventual modifications of behavior of the IBS due to this thermal treatment [1]. The steam sterilization temperature $\left(121^{\circ} \mathrm{C}\right.$ during $\left.21 \mathrm{~min}\right)$ has an inverse effect on the viscosity of the suspending polymer. Increasing the temperature decreases the viscosity because of weakening of molecular interaction. So, it is possible to study the effect of temperature on the stability of IBS in situ.

\section{Acknowledgements}

This work was supported by CPER "Biomatériaux S3" 2004-2008, Région Pays de la Loire. The help of Paul Pilet (Center of Electronic Microscopy, INSERM U791 CHU Nantes) for the image observations and granulometry analysis is acknowledged with gratitude.

\section{References}

[1] P. Weiss, O. Gauthier, J.M. Bouler, G. Grimandi and G. Daculsi, Bone 25 (1999) 67S-70S.

[2] G. Daculsi, P. Weiss, J.M. Bouler, O. Gauthier, F. Millot and E. Aguado, Bone 25 (1999) 59S-61S.

[3] J.M. Bouler, R.Z. LeGeros and G. Daculsi, Journal of Biomedical Materials Research 51 (2000) 680-4.

[4] J. Tritt-Goc and N. Pislewski, Journal of Controlled Release 80 (2002) 79-86.

[5] N. Sarkar, Journal of Applied Polymer Science. 24 (1979) 1073-1087.

[6] N. Sarkar and L.C. Walker, Carbohydrate Polymers 27 (1995) 177-185.

[7] A. Haque and E.R. Morris, Carbohydrate Polymers 22 (1993) 161-173.

[8] K. Kobayashi, C. Huang and T.P. Lodge, Macromolecules 32 (1999) 7070-7077.

[9] N. Sarkar, Carbohydrate Polymers 26 (1995) 195-203.

[10] J. Bosco, A. Fatimi, S. Quillard, J.M. Bouler and P. Weiss, Key Engineering Materials 330-332 (2007) 847-850.

[11] A. Shojaeia and R. Arefiniaa, Chemical Engineering Science 61 (2006) 7565-7578.

[12] C. Allain and M. Cloitre, Advances in Colloid and Interface Science 46 (1993) 129-138.

[13] M. Balastre, J.F. Argillier, C. Allain and A. Foissy, Colloids and Surfaces A 211 (2002) 145-156.

[14] C. Clasen and W.M. Kulicke, Progress in Polymer Science 26 (2001) 1839-1919. 